\title{
Development of Nutritious Fruit Leather by Blending Guava and Papaya
}

\author{
L. Jeebit Singh ${ }^{1 *}$ and R.B. Tiwari ${ }^{2}$ \\ ${ }^{1}$ Directorate of Horticulture and Soil Conservation, Manipur, India \\ ${ }^{2}$ Division of Post-Harvest Technology and Agricultural Engineering, ICAR-IIHR, Bengaluru, \\ Karnataka, India \\ *Corresponding author
}

\begin{tabular}{|l|}
\hline Ke y w o r d s \\
$\begin{array}{l}\text { Fruit leather, Fruit } \\
\text { bar, Blending, } \\
\text { Guava, Papaya }\end{array}$ \\
\hline Article Info \\
\hline $\begin{array}{l}\text { Accepted: } \\
\text { 07 June } 2019 \\
\text { Available Online: } \\
\text { 10 July } 2019\end{array}$ \\
\hline
\end{tabular}

A B S T R A C T
Blended guava 'Allahabad Safeda' and papaya 'Taiwan Red Lady' fruit leathers were prepared by blending their pulp at different ratio of 100:0, 80:20, 60:40, 50:50, 40:60, 20:80 and 0:100 respectively. Acidity at $0.3 \%$ using citric acid and KMS (potassium metabisulphite) at $600 \mathrm{ppm}$ was added to blended pulp and TSS adjusted to $20^{\circ} \mathrm{B}$ then dried in a cabinet drier at $55 \pm 5^{\circ} \mathrm{C}$ till the desired moisture content (15\% approx.) is achieved. Blended guava-papaya (40:60) leather was found best among other treatments in terms of quality and acceptability. It had a good yield of $26.78 \%$ with $15.75 \%$ moisture content and 0.59 water acidity which promises a good storability and safety. It was highly acceptable with maximum sensory acceptability in terms of colour, flavor and texture (total 80.78 out of 100 ) with acidity $1.22 \%$, reducing sugar $39.44 \%$, non-reducing sugar $29.41 \%$ and total sugar $68.85 \%$. It improved the nutritional value with $137.3 \mathrm{mg}$ per $100 \mathrm{~g}$ ascorbic acid and $1367.3 \mu \mathrm{g}$ carotenoids per $100 \mathrm{~g}$ of prepared leather. Non enzymatic browning (NEB) measured at optical density at $420 \mathrm{~nm}$ had 0.124 reading which was far below unacceptable level.

\section{Introduction}

Fruit leather or bar or slab is a self-stable confectionary, dehydrated product with soft gel like texture. It has a long shelf life and does not require refrigeration. It can be prepared from fresh pulp, frozen pulp or canned fruit. It is made by drying a very thin layer of fruit puree and other ingredients in cabinet drier in the form of leathery sheets
(Andress and Harrison, 1999). Natural fruit pulp based fruit bars are more tasty and nutritious since substantial quantity of dietary fibers, mineral, vitamins and other phytochemicals are present. Fruit leathers add value to fruit which may otherwise not acceptable for the fresh produce market.

Guava (Psidium guajava L.) and papaya (Carica papaya L.) are two commercially 
important fruit with unique flavor which are tasty, digestive and nutritious. Guavais a rich source of vitamin C content next to aonla while papaya is a rich source of beta-carotene (precursor of vitamin A) next to mango. Beside these both fruits contain other various health promoting phytochemicals like vitamins, minerals, antioxidant, dietary fibre, etc. However, both fruit have very short postharvest life leading to huge postharvest loss in addition to problems of seasonal glut. These problems can be curbed up to certain extent by various methods of processing.

Blending of different fruits by processing into nutritious fruit leather can be explored to obtain phyto-nutritional benefits from both fruits (Sreemathi et al., 2008; Dwivedi et al., 2015; Uttarwar et al., 2018). Guava fruit have white pulp with pleasant flavour and slight acidic taste, can be mixed with papaya having blood red pulp with good taste to give a quality product. Blending guava and papaya into a product will improve nutritional qualities, sensory qualities (colour, texture and flavor) and storage stability. Further, the good availability of both fruit almost throughout the year is another factor. Hence, an experiment to standardise nutritionally rich and tasty blended fruit leather from both fruits were carried out.

\section{Materials and Methods}

The present investigation was carried out at Division of Post-Harvest Technology, ICARIIHR, Bangalore. Guava var. 'Allahabad Safeda' and papaya var. 'Taiwan Red Lady' was procured from the farm of IIHR, Bangalore. Fully ripe fresh fruits uniform in size and shape, free from transportation injuries, bruises, insect damage and diseases which are uniformly ripened were selected. Both fruits were washed properly with running tap water to remove any adhering foreign matter. Guava fruits were peeled by lye peeling technique (using $0.5 \% \mathrm{NaOH}$ boiling solution for $2 \mathrm{~min}$.) then repeatedly washed using tap water while papaya fruits were hand peeled. To prevent browning, ascorbic acid $(100 \mathrm{mg} / 100 \mathrm{~g})$ was added to guava pulp. Both peeled fruits were cut into small pieces and pulped using a mixer. Pulp was then passed through a fine sieve to obtain a fine pulp separately.

The pulp from both guava and papaya fruits were mixed at seven different ratio of $\mathrm{T}_{1}$ 100:0, $\mathrm{T}_{2}-80: 20, \mathrm{~T}_{3}-60: 40, \mathrm{~T}_{4}-50: 50, \mathrm{~T}_{5}-$ 40:60, $\mathrm{T}_{6}-20: 80$ and $\mathrm{T}_{7}-$ 0:100 respectively. The total soluble solids and acidity were adjusted to $20{ }^{\circ} \mathrm{B}$ and $0.3 \%$ acidity. Preservative as KMS (potassium metabisulphite) at $600 \mathrm{ppm}$ was added in all the samples. Different treatment of mixed pulp of $1 \mathrm{~kg}$ was spread on stainless steel drier trays in the form of a sheet at the rate of $250 \mathrm{~g} / \mathrm{sq}$. ft. The trays were then kept for drying in a cabinet drier at $55 \pm 5^{\circ} \mathrm{C}$ till a moisture content of $15 \%$ (approx.). The dried sheets of fruit leather were weighted and cut into rectangular slabs of dimension $3.5 \times 7.5 \mathrm{~cm}$ and kept for equalization in air-tight plastic boxes overnight. Data regarding the yield of fruit bars were recorded.

Fresh pulp and blended dehydrated leathers were analyzed for various physical and biochemical constituents as per methods described by A.O.A.C. (1995). Total soluble solids were recorded using hand refractrometer (Erma, Japan), non-enzymatic browning (OD at $440 \mathrm{~nm}$ ) by UV visible spectrophotometer (Model T70, PG Instrument) and water activity by water activity meter (Rotronic, Hygro Lab). Organoleptic quality evaluation of blended guava and papaya fruit leather was done by a panel of semi-skilled judges (6) by adopting a hedonic rating system having 100 points with various sub-scores as colour (30), texture (30) and flavor (40). The experiment was laid out in completely randomized design comprising 
of 3 replications. The mean values were evaluated by critical difference (CD) test at 5 $\%$ level of significance by using ANOVA.

\section{Results and Discussion}

The physico-chemical composition of fresh guava pulp var. 'Allahabad Safeda' and papaya pulp var. 'Taiwan Red Lady' in terms of various parameters like moisture content, total solids, ascorbic acid, carotenoids, titratable acidity, reducing sugars, nonreducing sugars total sugars and recovery percentage are presented in Table 1.

Effect of different treatments on the yield of prepared samples are shown in Figure 1 and maximum yield was obtained in fruit leather made from guava pulp only $(29.18 \%)$ while lowest yield was obtained for product made from $100 \%$ papaya pulp $(24.07 \%)$. It was observed that higher blending ratio of guava resulted in significantly higher yield of finished product.

Higher total solids content of guava in the fresh produce is attributed to this result. This may be due to more total solids content of guava pulp than papaya pulp. Similar findings were reported by Basha et al., (2018) in the development of guava leather and Yilmaz et al., (2017) in pomegranate fruit leather.

Effects of blending on various physicochemical characteristic of prepared leathers are presented in Table 2. Initial moisture content among various treatments was nonsignificant and ranged from 13.89 to $15.75 \%$. This may be due to equal initial TSS content of pulp and uniform method of drying (Fulchand et al., 2015). Similarly water activity was also non-significant and ranged from 0.56 to $0.59 \mathrm{a}_{\mathrm{w}}$. As the pulp was concentrated due to removal of moisture during drying, other constituents were found enhanced in comparison to fresh sample
(Shende and Datta, 2019). Acidity content was significantly highest in plain guava leather $(1.46 \%)$ and lowest in plain papaya leather $(1.11 \%)$ and there was increase in acidity with percentage increase in guava pulp blended in various treatments (Ahmad et al., 2018). Plain guava leather had highest ascorbic acid content $(226.6 \mathrm{mg} / 100 \mathrm{~g})$ with no carotenoids content. While plain papaya leather had highest carotenoids content $(1600.2 \mu \mathrm{g} / 100 \mathrm{~g})$ and lowest ascorbic acid content $(43.8 \mathrm{mg} / 100 \mathrm{~g})$. Due to more content of ascorbic acid in guava, those treatments with more blending ratio of guava have higher ascorbic acid content (Vasanthakaalam et al., 2018). Blended guava and papaya fruit leather had improved ascorbic acid and carotenoids content due to contribution from both fruits. These results are in accordance with finding of Tiwari (2000) in blended guava-papaya RTS beverage. Maximum reducing sugar $(46.10 \%)$ and minimum non-reducing sugar $(21.89 \%)$ was observed in plain guava leather. While maximum non-reducing sugar $(32.83 \%)$ and minimum reducing sugar $(35.74 \%)$ in plain papaya leather.

Considerable increase in reducing sugar content with higher ratio of guava pulp was observed while reverse trends on non-reducing sugar. However, total sugar content was nonsignificant and it ranged from 65.67 to 73.57 $\%$. These results are in conformity with the observations made in papaya leather by Kumar et al., (2010) and Singh et al., (2016). Lowest non-enzymatic browning (0.121) was observed in plain guava leather while highest (0.187) in guava-papaya blend at 50:50. However, the extent of non-enzymatic browning in all treatments was far below the unacceptable level. The addition of potassium metabisulphite and additional ascorbic acid helped to achieved lower non-enzymatic browning (Chen and Martynenko, 2018; Tontul and Topuz, 2017). 
Plate.1 Blended guava-papaya leather $\left(\mathrm{T}_{1^{-}}\right.$100:0, $\mathrm{T}_{2^{-}}$80:20, $\mathrm{T}_{3^{-}}$60:40, $\mathrm{T}_{4}-50: 50, \mathrm{~T}_{5^{-}}$40:60, $\mathrm{T}_{6^{-}}$ 20:80 and $\mathrm{T}_{7^{-}}$0:100 guava and papaya respectively)

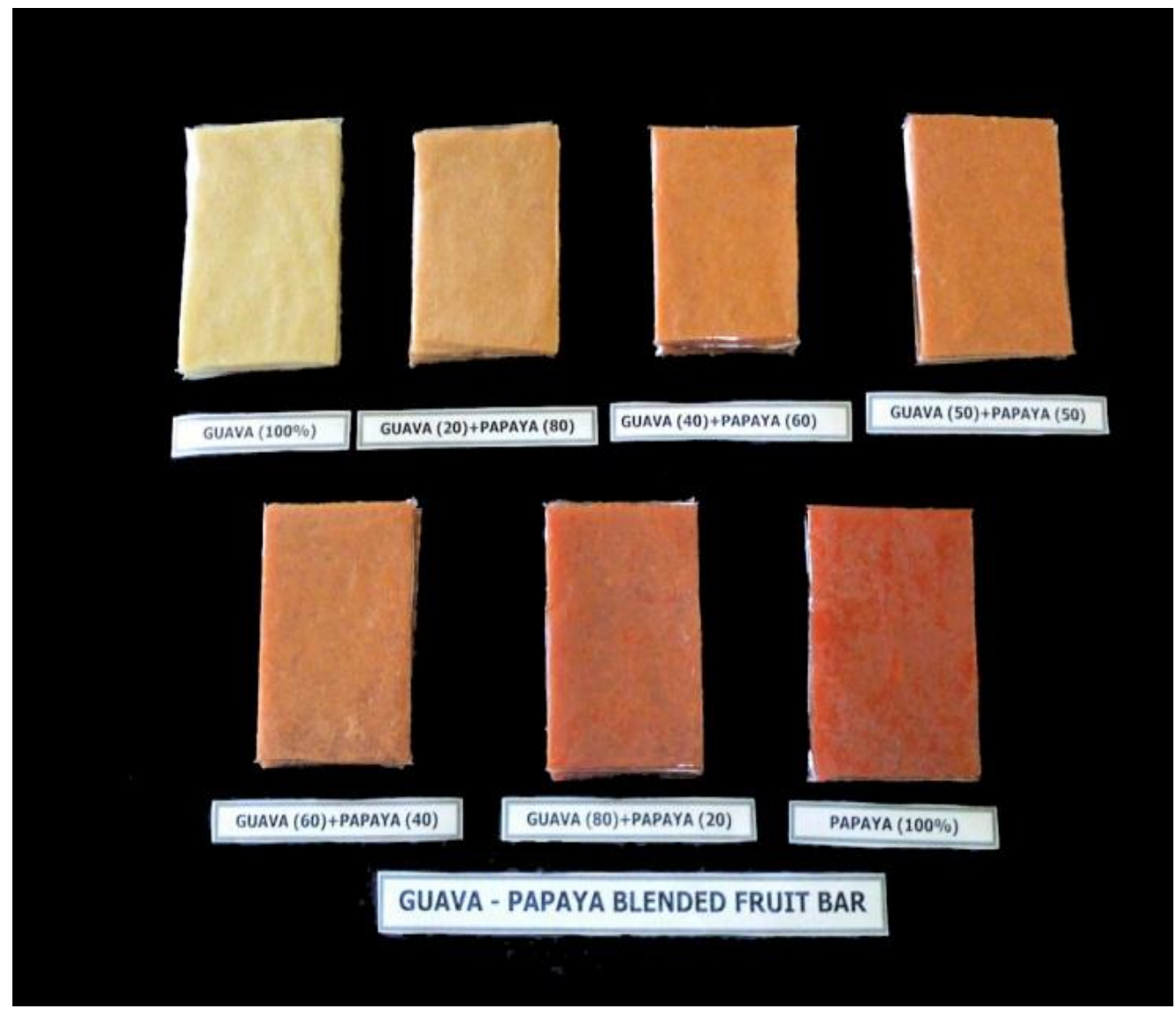

Table.1 Physico-chemical composition of the fresh guava var. 'Allahabad Safeda' and papaya var. 'Taiwan Red Lady's pulp used for the experiment

\begin{tabular}{|l|l|l|l|}
\hline S.No. & Chemical Parameters & Guava & Papaya \\
\hline 1. & Pulp Recovery $(\%)$ & 48.71 & 35.46 \\
\hline 2. & Moisture $(\%)$ & 89.35 & 88.97 \\
\hline 3. & Total Solids (TS) (\%) & 10.65 & 11.03 \\
\hline $\mathbf{4 .}$ & Acidity $(\%$ citric acid) & 0.44 & 0.25 \\
\hline $\mathbf{5 .}$ & Total Soluble Solids $\left({ }^{\circ}\right.$ Brix) & 8.73 & 12.20 \\
\hline 6. & Ascorbic acid $(\mathrm{mg} / 100 \mathrm{~g})$ & 225.2 & 51.41 \\
\hline 7. & Carotenoids $(\mathrm{mg} / 100 \mathrm{~g})$ & Nil & 13.18 \\
\hline 8. & Reducing Sugars $(\%)$ & 4.20 & 6.10 \\
\hline 9. & Non-reducing Sugars $(\%)$ & 1.79 & 1.21 \\
\hline $\mathbf{1 0 .}$ & Total Sugars $(\%)$ & 5.99 & 7.31 \\
\hline
\end{tabular}

*Means of three observations 
Table.2 Physico-chemical properties of blended guava and papaya fruit leather

\begin{tabular}{|c|c|c|c|c|c|c|c|c|c|}
\hline Treatment & $\begin{array}{l}\text { Moistur } \\
\text { e }(\%)\end{array}$ & $\begin{array}{l}\text { Water } \\
\text { Activity }\end{array}$ & $\begin{array}{l}\text { Acidity } \\
(\%)\end{array}$ & $\begin{array}{l}\text { Ascorbic acid } \\
(\mathrm{mg} / \mathbf{1 0 0 g})\end{array}$ & $\begin{array}{l}\text { Carotenoids } \\
(\mu \mathrm{g} / \mathbf{1 0 0 g})\end{array}$ & $\begin{array}{l}\text { Reducing } \\
\text { Sugar }(\%)\end{array}$ & $\begin{array}{l}\text { Non-reducing } \\
\text { Sugar }(\%)\end{array}$ & $\begin{array}{l}\text { Total Sugar } \\
(\%)\end{array}$ & $\begin{array}{l}\text { NEB (OD } \\
\text { at } 420 \mathrm{~nm})\end{array}$ \\
\hline $\mathbf{T}_{1}$ & 14.16 & 0.59 & 1.46 & 226.6 & 0.0 & 46.10 & 21.89 & 67.99 & 0.121 \\
\hline $\mathbf{T}_{2}$ & 14.39 & 0.58 & 1.43 & 206.3 & 880.3 & 44.42 & 22.01 & 66.43 & 0.148 \\
\hline $\mathbf{T}_{3}$ & 14.26 & 0.58 & 1.29 & 180.6 & 998.3 & 41.40 & 26.73 & 68.13 & 0.156 \\
\hline $\mathbf{T}_{4}$ & 13.92 & 0.58 & 1.25 & 158.4 & 1224.5 & 44.50 & 27.48 & 73.07 & 0.187 \\
\hline $\mathbf{T}_{5}$ & 15.75 & 0.59 & 1.22 & 132.6 & 1380.2 & 39.44 & 29.41 & 68.85 & 0.124 \\
\hline $\mathbf{T}_{6}$ & 13.89 & 0.56 & 1.14 & 116.3 & 1529.1 & 37.99 & 32.69 & 69.97 & 0.158 \\
\hline $\mathbf{T}_{7}$ & 13.99 & 0.57 & 1.11 & 43.8 & 1600.2 & 36.49 & 32.83 & 69.32 & 0.173 \\
\hline SEm \pm & 0.64 & 0.03 & 0.08 & 4.7 & 38.0 & 0.90 & 0.81 & 1.24 & 0.016 \\
\hline CD at $5 \%$ & NS & NS & 0.23 & 14.3 & 115.5 & 2.75 & 2.44 & NS & NS \\
\hline
\end{tabular}

Table.3 Sensory score of blended guava and papaya fruit leather

\begin{tabular}{|c|c|c|c|c|c|}
\hline \multicolumn{2}{|c|}{ Treatment } & \multirow{2}{*}{$\begin{array}{c}\text { Colour (30) } \\
22.15\end{array}$} & \multirow{2}{*}{$\begin{array}{c}\text { Texture(30) } \\
23.46\end{array}$} & \multirow{2}{*}{$\begin{array}{c}\text { Flavour(40) } \\
31.14\end{array}$} & \multirow{2}{*}{\begin{tabular}{|c|} 
Overall acceptability(100) \\
79.46
\end{tabular}} \\
\hline $\mathbf{T}_{1}$ & Guava pulp $100 \%$ & & & & \\
\hline $\mathbf{T}_{2}$ & Guava pulp $80 \%$ and papaya pulp $20 \%$ & 22.43 & 24.36 & 28.71 & 73.50 \\
\hline $\mathbf{T}_{\mathbf{3}}$ & Guava pulp $60 \%$ and papaya pulp $40 \%$ & 22.71 & 22.57 & 26.14 & 71.43 \\
\hline $\mathbf{T}_{4}$ & Guava pulp $50 \%$ and papaya pulp $50 \%$ & 23.43 & 24.36 & 29.33 & 77.12 \\
\hline $\mathbf{T}_{5}$ & Guava pulp $40 \%$ and papaya pulp $60 \%$ & 25.00 & 25.57 & 30.21 & 80.78 \\
\hline $\mathbf{T}_{6}$ & Guava pulp $20 \%$ and papaya pulp $80 \%$ & 24.86 & 24.58 & 27.33 & 76.76 \\
\hline $\mathbf{T}_{7}$ & Papaya pulp $100 \%$ & 25.57 & 24.14 & 26.14 & 78.86 \\
\hline \multicolumn{2}{|c|}{ SEm \pm} & 0.67 & 0.78 & 0.84 & 1.89 \\
\hline \multicolumn{2}{|c|}{ CD at $5 \%$} & 2.03 & NS & 2.53 & 5.73 \\
\hline
\end{tabular}


Fig.1 Effect of different blending ratio on the yield of blended guava and papaya fruit leather

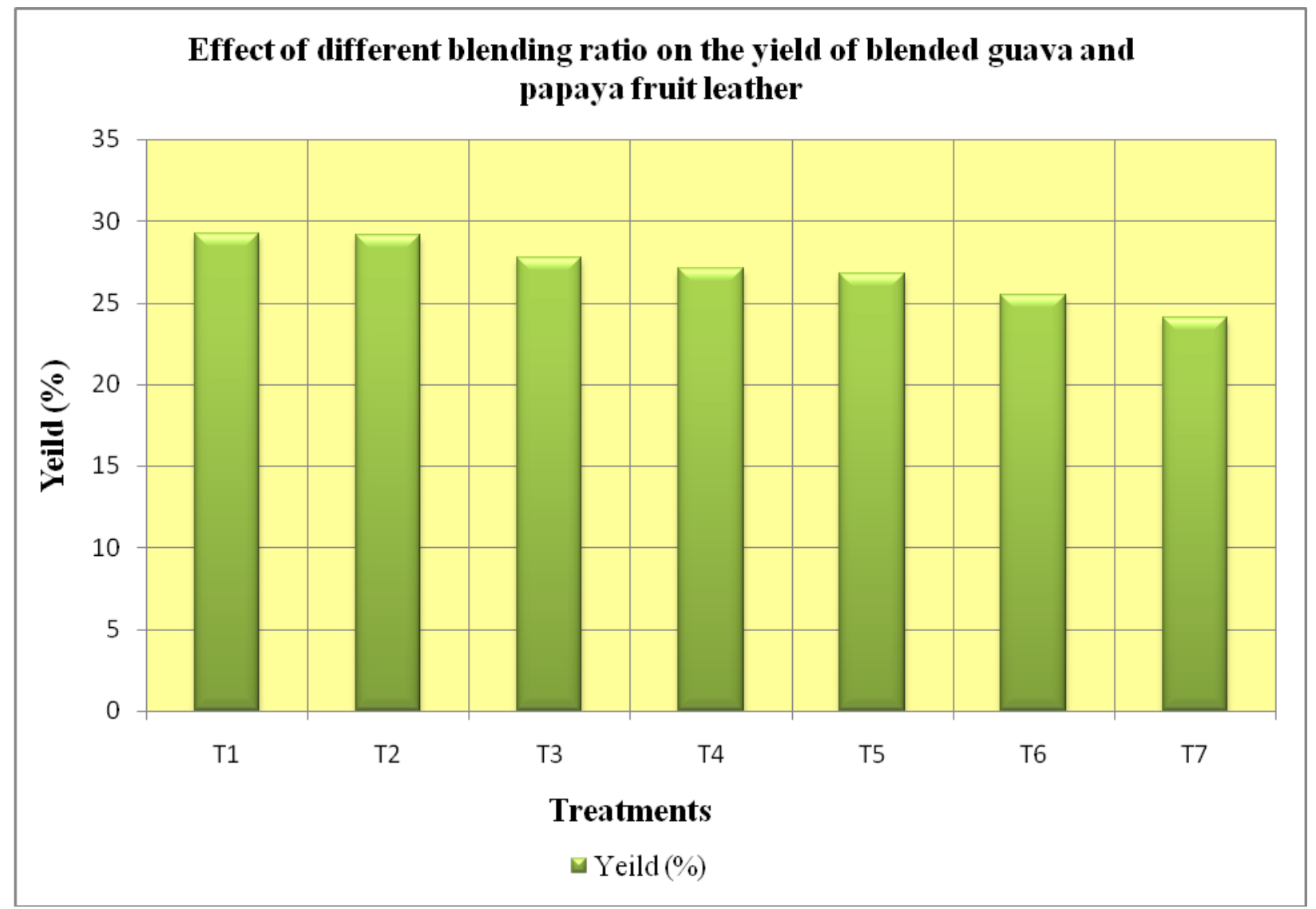

Sensory evaluation shows that all combination was highly acceptable as shown in Table 3. The colour score indicated plain papaya leather was superior to other with a maximum colour score of 25.57 which was at par with $\mathrm{T}_{5}$ and $\mathrm{T}_{6}$. The bright red colour due to papaya pulp was very attractive to the judges while plain guava leather was least preferred. The texture score by judges were non-significant (22.57 to 25.57) which might be due to non-significant moisture content (Dhake et al., 2018). Sensory score for flavour was maximum in plain guava leather (31.14) which was also at par with $\mathrm{T}_{4}$ and $\mathrm{T}_{5}$ while least in plain papaya (26.14). This indicated that least favoured papaya pulp can be economically blended with guava without affecting the acceptability. Overall acceptability score indicated that fruit leather made by blending guava and papaya at 40:60
(80.78 out of 100) ranked best in terms of colour, texture and flavour. It was also at par with plain guava (79.46 out of 100) and plain papaya (78.86 out of 100). These results are in conformity with the findings on organoleptic properties of wild apricot bar by Raju et al., (2012) and in mixed fruit leather from apple, banana and pineapple (Offia-Olua and Ekwunife, 2015).

In blended guava and papaya fruit leather, physico-chemical and sensory evaluation showed significant differences with respect to yield, acidity, ascorbic acid, carotenoids, reducing sugar and non-reducing sugar content, non-enzymatic browning, as well as sensory attributes such as colour and texture. Blended fruit leather made using guava pulp and papaya pulp in the ratio of 40:60 $\left(\mathrm{T}_{5}\right)$ was found superior to other treatments with good 
nutritional content $(137.3 \mathrm{mg} / 100 \mathrm{~g}$ ascorbic acid and $1367.3 \mu \mathrm{g} / 100 \mathrm{~g}$ carotenoids) and maximum sensory qualities (80.78 out of 100). Therefore, blending of guava and papaya pulp for preparation of leather has great potential and it can be successfully explored for sustainable use of these highly perishable commodities.

\section{Acknowledgement}

The authors acknowledge the help rendered by Mrs. Sarojini Jalali and Mr. Reddappa, Technical Officers, Division of PHT and Agri. Engineering, ICAR-IIHR, Bangalore in carrying out this experiment.

\section{References}

A.O.A.C. 1995. Official Methods of Analysis of the Association of Official Analytical Chemists, II Edn., Washington DC.

Ahmad, N., Shafii, S. N., Hassan, N. H., Rajab, A., and Othman, A. 2018. Physicochemical and sensorial properties of optimised rosellepineapple leather. Malaysian J. Analytical Sci. 22(1), 35-44.

Andress, E. L. and Harrison, J. A. 1999. So easy to preserve (4th ed.). Athens: University of Georgia Cooperative Extension Service.

Basha, S. J., Godghase Shivshankar, N., Pande, S., and Shaziya, V. 2018. Studies on development of guava leather as a novel product. Int. J. Chem. Stu. 6(6), 1920-1929.

Chen, Y. and Martynenko, A. 2018. Combination of hydrothermodynamic (HTD) processing and different drying methods for natural blueberry leather. LWT. 87, 470-477.

Dhake, R. S., Kotecha, P. M. and Thorat, S. S. 2018. Physico-Chemical properties, chemical composition and sensory qualities of pineapple fruit leather during storage. Bioinfolet. 15(2), 232234.

Dwivedi, S. K., Mishra, V., Saran, S.and Roy, S. K. 2015. Studies on preparation and preservation of fruit leather by blending indigenous fruits viz. bael and aonla pulp. J. Postharvest Tech. 3(2), 36-42.

Fulchand, C. R., Gunvantrao, J. V. and Pralhad, I. M. 2015. Studies on effect of Drying Temperature and Storage Time on Vitamin C Retention Capacity and Moisture Content of Papaya-Apple Fruit Leather. Asian J. Dairy Food Res. 34(4), 319-323.

Kumar, R., Patil, R. T. and Mondal, G. 2010. Development and evaluation of blended papaya leather. Acta-Horti. 851, 565570.

Offia-Olua, B. I. and Ekwunife, O. A. 2015. Production and evaluation of the physico-chemical and sensory qualities of mixed fruit leather and cakes produced from apple (Musa pumila), banana (Musa sapientum), pineapple (Ananascomosus). Nigerian Food J. 33(1), 22-28.

Raju, M. P., Shireesha, B., Sravanthi, B. and Kuna Aparna. 2012. Development of lycopene enriched mixed fruit bar. J. Res. ANGRAU. 40(3), 67-68.

Sharma, S. K. Chaudhary, S. P. Rao, V. K. Yadav, V. K. and Bisht, T. S. 2013. Standardization of technology for preparation and storage of wild apricot fruit bar. J. Food Sci. Technol. 50(4), 784-790.

Shende, D., and Datta, A. K. 2019. Refractance window drying of fruits and vegetables: a review. J. Sci. Food Agri. 99(4), 1449-1456.

Singh, A., Singh, Y., Kumar, L., Shalini, S. and Kumar, R. 2016. Effect of different levels of citric acid on quality and storage stability of sugar and jaggery based papaya (Carica papaya L.) fruit bar. J. App. Nat. Sci. 8(2), 1063-1067. 
Sreemathi, M., Sankaranarayanan, R. and Balasubramanyan, S. 2008. Sapotapapaya bar. Madras Agri. J. 95(1/6), $170-173$.

Tiwari, R. B. 2000. Studies of blending of guava and papaya pulp for RTS beverage. Indian Food Pack. 54, 68-72.

Tontul, I., and Topuz, A. 2017. Effects of different drying methods on the physicochemical properties of pomegranate leather (pestil). LWT. 80, 294-303.

Uttarwar, V. V., Taur, A. T.and Sawate, A. R. 2018. Development and organoleptic evaluation of mixed fruit leather from bael and Aonla pulp. Int. J. Chem. Stu. 6(2): $2823-2825$

Vasanthakaalam, H., Muhimpundu, J., Karayire, A. and Fabien, M. 2018. Stability of vitamin $C$ and $\beta$-carotene during processing of papaya guava fruit leather. Carpathian J. Food Sci. Tech. 10(4), 104-115.

Yilmaz, F. M., Yüksekkaya, S., Vardin, H. and Karaaslan, M. 2017. The effects of drying conditions on moisture transfer and quality of pomegranate fruit leather (pestil). J. Saudi Soc. Agri. Sci. 16(1), 33-40.

\section{How to cite this article:}

Jeebit Singh, L. and Tiwari, R.B. 2019. Development of Nutritious Fruit Leather by Blending Guava and Papaya. Int.J.Curr.Microbiol.App.Sci. 8(07): 813-820. doi: https://doi.org/10.20546/ijcmas.2019.807.098 